\title{
The Long Non-Coding RNA Landscape of Atherosclerotic Plaques
}

\author{
Weronika Kraczkowska ${ }^{1}$ [D . Paweł Piotr Jagodziński ${ }^{1}$
}

Published online: 10 October 2019

(c) The Author(s) 2019

\begin{abstract}
Currently, cardiovascular diseases continue to be the leading cause of death worldwide; therefore, atherosclerosis remains one of the most crucial public health problems. This chronic and complex disease is considered to be a result of aberrant lipid homeostasis and inflammation of the inner wall of arteries that leads to plaque development. In recent years, a specific class of non-coding RNAs that are characterised by transcript lengths longer than 200 nucleotides, called long non-coding RNAs (lncRNAs), has emerged. Moreover, a growing body of evidence indicates that deregulation of lncRNA expression may contribute to the development of many diseases. Despite continuous efforts in deciphering the molecular basis of atherosclerotic plaque (AP) formation, many aspects of this process remain elusive. Therefore, continuing efforts in this area should remain the highest priority in the coming years. Establishment of a standardised experimental pipeline and validation of lncRNAs as possible relevant biomarkers for cardiovascular disease would enable the translation of gathered findings into clinical practice.
\end{abstract}

\section{Key Points}

1. Recent studies suggest that long non-coding RNAs (lncRNAs) could have pivotal role in the development of many diseases.

2. Deciphering the functions of IncRNAs associated with atherosclerotic plaque formation could lead to finding new therapeutic targets or even biomarkers for arthrosclerosis.

\section{Introduction}

\subsection{Aetiology of Atherosclerosis}

Atherosclerotic plaque (AP) formation in the inner walls of the arteries is a leading trigger of cardiovascular diseases (CVDs), including coronary artery disease (CAD)

Weronika Kraczkowska

nika.kracz@gmail.com

1 Department of Biochemistry and Molecular Biology, Poznań University of Medical Science, 6 Święcickiego Street, 60-781 Poznan, Poland and myocardial infarction (MI), and therefore constitutes a significant health threat to modern society [1]. The interplay of multiple genetic and environmental factors underlies atherosclerosis development. Moreover, the list of these factors is continuously expanding [2]. From the traditional point of view, atherosclerosis is a disease connected with a chronic inflammatory state of the arterial walls accompanied by aberrant lipid metabolism [3, 4]. According to the endothelial injury-response theory, initial lesion formation is a result of endothelial cell (EC) pro-inflammatory activation and phenotypic changes that could be elicited by either chemical agents or physical injuries [5]. Through the course of this process, increased permeability of the endothelium along with the production of cell surface adhesion molecules leads to infiltration of monocytes or other molecules, e.g. lipoproteins into the intima. Subsequently, monocytes differentiate into macrophages that take up these lipoproteins to finally become foam cells, whereas smooth muscle cells proliferate and migrate from the media to the intima. Additionally, synthesis of extracellular matrix components is increased. As a result, atherogenesis progression leads to the accumulation of cellular, extracellular, and lipid material within the arterial wall, forming APs [3,5]. During atherosclerosis development, plaques exhibit different histological compositions and structures and are therefore classified into eight categories according to a report by the American Heart Association (AHA), reflecting the stages of the disease [6]. 
At the molecular level, bioinformatic analysis indicated that 5784 messenger RNAs (mRNAs) and 654 transcripts identified as long non-coding RNAs (lncRNAs) were differentially expressed in early plaques versus advanced APs [7].

\subsection{Biology of Long Non-Coding RNAs (IncRNAs)}

Interestingly, a whole range of studies indicates that lncRNAs contribute considerably to the development of various diseases, including atherosclerosis. The data accumulated thus far show that IncRNAs encompass 270,044 transcripts in the human genome [8], constituting one of the most abundant groups of non-coding RNAs (ncRNAs) [9]. The transcripts comprising lncRNAs are mainly characterised by a strand length longer than 200 nucleotides and a low protein-coding capacity [10]. Since many ncRNAs do not have a thoroughly investigated annotation, there are several approaches for classifying lncRNAs. One of these approaches is based on their location and direction of transcription according to the protein-coding gene, and thus divides lncRNAs into different classes: antisense (transcribed in the antisense orientation to the protein-coding genes), bidirectional (transcribed in the opposite direction of the protein-coding genes), overlapping (transcribed in the same direction as the protein-coding genes and sharing the same sequence), sense intronic (transcribed in the same direction as the protein-coding gene but from an intronic sequence) and intergenic (transcribed from an intergenic region of the genome, $>10 \mathrm{~kb}$ from protein-coding genes) [11]. lncRNA transcripts can be localised in the nucleus or cytosol [12] and are derived from both the nuclear and mitochondrial genomes [13, 14]. The abundance and diversity of lncRNAs reflect their range of functions, which encompass IncRNA:RNA, lncRNA:protein and lncRNA:chromatin interactions [15] and can be categorised into four different archetypes describing their molecular mode of action: signalling archetype-lncRNAs that can serve as molecular signals, being transcribed only during specific cell processes; decoy archetype-IncRNAs that bind to and titrate away proteins and other regulatory RNAs; guide archetype-lncRNAs that bind to and direct ribonucleoprotein complexes to the proper localization; and scaffold archetype-lncRNAs that function as a platform to molecular components, allowing them to be assembled together [16]. A more detailed description of IncRNA classification, structure, biogenesis and function can be found in recently published articles (for detailed information, see Amin et al. [17] and Ransohoff et al. [18]). Many lncRNAs exhibit cell type-specific expression patterns, providing an excellent opportunity to investigate the relevance of their aberrant expression in different diseases [19]. However, low conservation of IncRNAs across species impedes the use of animal models to investigate their function in humans [20].
In this article, we summarise the recent findings in the study of lncRNA in human APs. Rather than discussing the relevance of lncRNAs in all models used in atherosclerosis research, we focus only on human tissues and cells.

\section{Utility of Plaques for Studies Regarding IncRNA Relevance in Atherosclerosis}

With the advent of novel technologies, especially next-generation sequencing and microarrays, it has become possible to employ global transcriptome profiling to identify RNAs that are dysregulated in many diseases [21]. Scientists use various strategies to elucidate the biological function and mode of action of lncRNAs in atherosclerosis. Many of the strategies apply in vitro experiments using cell lines to reflect specific processes in atherosclerosis. There is an approach based on APs that provides an opportunity to investigate complex and multilayer cell environments; however, several ambiguities and technical obstacles limit its usage for lncRNA study. First, there are ethical as well as technical restrictions regarding obtaining specimens because they can be collected only from patients subjected to the specific types of invasive surgical treatments (e.g. endarterectomy, bypass grafting, amputation, transplantation or autopsy). A comparison between gene expression levels in advanced APs obtained from surgery and autopsy showed that 500 genes were differentially expressed at the mRNA level [22], which could cast doubts on the suitability of autopsy material for lncRNA analysis. Some research, despite combining different kinds of plaque sources (i.e. cadavers and patients), still faces the issue of small sample size (Table 1). In this context, it could be reasonable to use the collections deposited in biobanks, e.g. the Biobank of Karolinska Endarterectomy whose resources also allows the results of the investigation to be related to additional clinical parameters [23]. In addition, the demographic and clinical characteristics of the study patients could have a profound contribution to the interpretation of the lncRNA expression data; for example, results from expression profiling study have demonstrated altered gene expression associated with statin (HMG-CoA reductase inhibitor) treatment [23]. Given that, it would be reasonable to validate the influence of medical treatment on the expression of lncRNA. Second, analysis of the cellular origin of lncRNAs may be hindered by an insufficient amount of harvested tissue sample to allow simultaneous gene expression analysis and fluorescent in situ hybridization (FISH) [24]. Third, the choice of control non-atherosclerotic samples is even more strictly limited and varies from using the peripheral end of the same lesion to choosing independently from the sample and could also be derived from the same patients as well as from different donors with no evidence of atherosclerosis (Table 1). However, different 
Table 1 Characteristics of atherosclerotic plaques and controls used in a few examples of long non-coding RNA studies

\begin{tabular}{|c|c|c|c|c|c|c|}
\hline $\operatorname{lncRNA}$ & Source of plaques & Evaluation of plaques & $\begin{array}{l}\text { Num- } \\
\text { ber of } \\
\text { plaques }\end{array}$ & Source of controls & $\begin{array}{l}\text { Number } \\
\text { of con- } \\
\text { trols }\end{array}$ & References \\
\hline \multirow[t]{2}{*}{ GAS5 } & Carotid artery & ICA stenosis $>70 \%$ & 8 & $\begin{array}{l}\text { Healthy aortic tissue sur- } \\
\text { rounding the plaque }\end{array}$ & 8 & {$[61]$} \\
\hline & Aorta from patients & Not described & 11 & Aorta from cadavers & 11 & {$[62]$} \\
\hline HOTAIR & $\begin{array}{l}\text { ECs of coronary artery } \\
\text { plaque from patients and } \\
\text { cadavers }\end{array}$ & Coronary angiography & 40 & $\begin{array}{l}\text { Corresponding vascular wall } \\
\text { from patients and cadavers }\end{array}$ & 40 & [115] \\
\hline \multirow[t]{2}{*}{ MALAT1 } & Coronary artery & CA stenosis $>50 \%$ & 20 & $\begin{array}{l}\text { Internal mammary artery of } \\
\text { plaque donors }\end{array}$ & 20 & [24] \\
\hline & Coronary artery & CA stenosis $>50 \%$ & 127 & $\begin{array}{l}\text { Aorta and iliac artery from } \\
\text { organ donors }\end{array}$ & 10 & [87] \\
\hline \multirow[t]{2}{*}{$R P 11-7146181$} & Carotid artery & $\begin{array}{l}\text { Histopathological confirma- } \\
\text { tion of atherosclerosis }\end{array}$ & 12 & $\begin{array}{l}\text { Renal artery of non-athero- } \\
\text { sclerotic patients }\end{array}$ & 12 & {$[122]$} \\
\hline & $\begin{array}{l}\text { Carotid artery or abdominal } \\
\text { artery }\end{array}$ & $\begin{array}{l}\text { Grade V or VI atheroscle- } \\
\text { rosis according to AHA } \\
\text { classification }\end{array}$ & 3 & $\begin{array}{l}\text { An artery from a cadaver and } \\
\text { a healthy artery of an AP } \\
\text { donor }\end{array}$ & 3 & \\
\hline
\end{tabular}

$A H A$ the American Heart Association, AP atherosclerotic plaque, $C A$ coronary artery, ECs endothelial cells, GAS5 growth arrest-specific 5, HOTAIR HOX transcript antisense RNA, ICA internal carotid artery, IncRNA long non-coding RNA, MALAT1 metastasis-associated lung adenocarcinoma transcript 1

localisation of the control and APs may have an influence on the research results due to variations in individual gene expression [24]. Fourth, plaques exhibit composition variability, even along the length of the same lesion, and their evaluation in the study is performed in many different ways (Table 1), e.g. by histological assessment and classification [6]. Due to the previously mentioned restrictions and several difficulties that limit detection by non-invasive methods of the early stages of the disease [25], mainly advanced types of lesions are included in the studies, impeding investigation concerning the mechanisms underlying the progression of atherosclerosis.

\section{IncRNAs in Atherosclerotic Plaques (APs)}

Among the lncRNAs with altered expression in APs, there are newly identified lncRNAs as well as IncRNAs with previously characterised functions or mechanisms of action (Table 2), in many cases not yet associated with atherosclerosis or any other CVDs. Taking this into account, in this review, we provide comprehensive insight into the current knowledge regarding lncRNAs with aberrant expression in APs compared to healthy arteries (Fig. 1).

\subsection{LncRNAs Upregulated in APs in Comparison with Healthy Tissue}

\subsubsection{H19}

Imprinted maternally expressed transcript (H19) is one of the first described lncRNAs. H19 expression is thought to be upregulated during embryogenesis and downregulated postnatally in most tissues [26]. Its re-expression has been observed in human APs, especially in actin-enriched cells with smooth muscle characteristics; however, some cells with probably endothelial origin also exhibited expression of $H 19$ [27]. Interestingly Hofmann et al. [28] indicated that expression of $H 19$ was higher in endothelium of healthy arteries than in APs. Moreover, in APs its expression was mainly restricted to ECs from intraplaque vessels [28]. The abovementioned discrepancy in the results obtained suggests a need for further investigations concerning the cell type-specific pattern of $H 19$ expression in AP. Subsequent research has shown that the $H 19$ gene polymorphism among the Chinese population is associated with CAD [29]. Moreover, the elevated expression of $H 19$ observed in blood samples of atherosclerotic patients [30-32] indicates that this lncRNA could serve as a potential biomarker for CAD [32]. It is possible that the role of $H 19$ in lesion development is connected with homocysteine, elevated levels of which in the bloodstream may be a risk factor for atherosclerosis [34]. Of note, homocysteine facilitated vascular smooth muscle cell (VSMC) proliferation in vitro [35, 36]. Stimulation of VSMCs with homocysteine led to increased H19 expression 
Table 2 Summary of long non-coding RNAs with altered expression in atherosclerotic plaques

\begin{tabular}{|c|c|c|c|c|c|}
\hline Approved symbol & Gene ID & $\begin{array}{l}\text { Expres- } \\
\text { sion }\end{array}$ & Regulated cellular processes & $\begin{array}{l}\text { Expression in cell lines /types } \\
\text { related to atherosclerosis }\end{array}$ & References \\
\hline ANRIL & 100048912 & $\uparrow$ & $\begin{array}{l}\text { Adhesion, apoptosis, inflam- } \\
\text { mation, migration, nucleolar } \\
\text { stress, transmigration, prolif- } \\
\text { eration, viability }\end{array}$ & $\begin{array}{l}\text { Adventitial fibroblasts, } \\
\text { CD68-positive macrophages, } \\
\text { EA.hy926, iPSC-derived } \\
\text { macrophages, MonoMac, } \\
\text { HCAECs, HCSMs, HMEC, } \\
\text { HuAoVSMCs, HUVECs, } \\
\text { human monocyte-derived } \\
\text { macrophages, PBMCs, } \\
\text { VSMCs }\end{array}$ & $\begin{array}{l}{[24,46-48,51,} \\
52,55,56,126]\end{array}$ \\
\hline$B A N C R$ & 100885775 & $\uparrow$ & Migration, proliferation & VSMCs & [81] \\
\hline CHROME & ENSG00000223960 & $\uparrow$ & Cholesterol efflux & $\begin{array}{l}\text { B cells CD19, CD14 mono- } \\
\text { cytes, PBMCs, regulatory } \\
\text { T cells, smooth muscle cells, } \\
\text { CD3 T cells, CD8 T cells, } \\
\text { CD4 T helper cells, THP- } \\
\text { 1-derived macrophages }\end{array}$ & [74] \\
\hline GAS5 & 60674 & $\uparrow$ & $\begin{array}{l}\text { Activation, angiogenesis, } \\
\text { apoptosis, autophagy, inflam- } \\
\text { mation migration, phenotypic } \\
\text { switching, proliferation, tube } \\
\text { formation, vasoconstrictors } \\
\text { production, viability }\end{array}$ & $\begin{array}{l}\text { HAECs, HCAECs, HUVE-12, } \\
\text { HUVECs, THP-1-derived } \\
\text { macrophages, U937, VSMCs }\end{array}$ & {$[61-64,66-69]$} \\
\hline$H 19$ & 283120 & $\uparrow$ or $\downarrow$ & $\begin{array}{l}\text { Apoptosis, autophagy, inflam- } \\
\text { mation, mineralisation, } \\
\text { proliferation, senescence }\end{array}$ & $\begin{array}{l}\text { HA-VSMCs, hCoAECs, } \\
\text { HUVECs, PBMCs, T/G HA- } \\
\text { VSMCs, VSMCs }\end{array}$ & $\begin{array}{l}{[27,28,30,32,} \\
33,38-40,125]\end{array}$ \\
\hline HOTTIP & 100316868 & $\uparrow$ & Migration, proliferation & HUVECs & {$[83]$} \\
\hline $\begin{array}{l}\text { HYMAI, KIAA1656, } \\
\text { LOC } 339803, \\
\text { LOC730101 }\end{array}$ & $\begin{array}{l}57061 \text { (HYMAI), } \\
85371 \text { (KIAA1656), } \\
339803 \text { (LOC339803), } \\
730101 \text { (LOC730101) }\end{array}$ & $\uparrow$ & $\begin{array}{l}\text { Probably a role in the cellular } \\
\text { response to hypoxia }\end{array}$ & HUVECs & {$[85]$} \\
\hline LINC00305 & 221241 & $\uparrow$ & $\begin{array}{l}\text { Apoptosis, inflammation, phe- } \\
\text { notypic switching, prolifera- } \\
\text { tion }\end{array}$ & $\begin{array}{l}\text { HASMCs, HUVECs, PBMCs, } \\
\text { THP-1 }\end{array}$ & {$[77,78]$} \\
\hline LINC00968 & 100507632 & $\uparrow$ & Migration, proliferation & ECs & [84] \\
\hline MIAT & 440823 & $\uparrow$ & Apoptosis, proliferation & $\begin{array}{l}\text { EA.hy926, HA-VSMCs, } \\
\text { HMVECs, HUVECs, U937 }\end{array}$ & {$[24,73,127]$} \\
\hline$R N C R 3$ & 157627 & $\uparrow$ & $\begin{array}{l}\text { Apoptosis, migration, prolifera- } \\
\text { tion }\end{array}$ & HUVECs, VSMCs & [79] \\
\hline SMILR & ENSG00000255364 & $\uparrow$ & $\begin{array}{l}\text { Maintenance of synthetic phe- } \\
\text { notype, proliferation }\end{array}$ & $\begin{array}{l}\text { CASMCs, HCASMCs, } \\
\text { HSVECs, HSVSMCs }\end{array}$ & {$[75,76]$} \\
\hline SNHG6, Zfas1 & $\begin{array}{c}641638 \text { (SNHG6), } \\
441951 \text { (Zfas1) }\end{array}$ & $\uparrow$ & Unknown & Unknown & {$[61]$} \\
\hline APPAT & ENSG00000230606 & $\downarrow$ & $\begin{array}{l}\text { Probably maintaining the con- } \\
\text { tractile phenotype of VSMCs }\end{array}$ & VSMCs & {$[123]$} \\
\hline FENDRR & 400550 & $\downarrow$ & Unknown & Unknown & {$[112]$} \\
\hline HOTAIR & 100124700 & $\downarrow$ & $\begin{array}{l}\text { Apoptosis, ox-LDL uptake, } \\
\text { inflammation, migration, oxi- } \\
\text { dative stress, proliferation }\end{array}$ & $\begin{array}{l}\text { ECs, HAECs, HUVECs, } \\
\text { PBMCs, THP-1-derived } \\
\text { macrophages }\end{array}$ & {$[115,116,119]$} \\
\hline lincRNA-p21 & 102800311 & $\downarrow$ & Apoptosis, proliferation & PBMCs, VSMCs & {$[112,113]$} \\
\hline MALAT1 & 378938 & $\downarrow$ & $\begin{array}{l}\text { Apoptosis, endothelial-to- } \\
\text { mesenchymal transition, } \\
\text { inflammation, lipid uptake, } \\
\text { migration, proliferation, } \\
\text { pyroptosis }\end{array}$ & $\begin{array}{l}\text { EA.hy926, HAECs, HCAECs, } \\
\text { HCMEC-C, HMVEC- } \\
\text { L, HUVECs, HPAECs, } \\
\text { HPASMCs, THP1-derived } \\
\text { macrophages, VSMCs }\end{array}$ & $\begin{array}{l}{[24,85,89,91} \\
93-95,97 \\
99-101]\end{array}$ \\
\hline
\end{tabular}


Table 2 (continued)

\begin{tabular}{|c|c|c|c|c|c|}
\hline Approved symbol & Gene ID & $\begin{array}{l}\text { Expres- } \\
\text { sion }\end{array}$ & Regulated cellular processes & $\begin{array}{l}\text { Expression in cell lines /types } \\
\text { related to atherosclerosis }\end{array}$ & References \\
\hline$N E X N-A S 1$ & 374987 & $\downarrow$ & $\begin{array}{l}\text { Adhesion, inflammation, migra- } \\
\text { tion }\end{array}$ & HUVECs, THP-1, VSMCs & {$[120]$} \\
\hline RP11-714G18.1 & ENSG00000250410.1 & $\downarrow$ & $\begin{array}{l}\text { Adhesion, apoptosis, migration, } \\
\text { NO production, proliferation, } \\
\text { tube formation }\end{array}$ & HA-VSMCs, HUVECs & {$[122]$} \\
\hline SENCR & 100507392 & $\downarrow$ & $\begin{array}{l}\text { Angiogenesis, cell adherence, } \\
\text { embryonic stem cells differen- } \\
\text { tiation to ECs, maintenance of } \\
\text { contractile phenotype, migra- } \\
\text { tion, proliferation }\end{array}$ & $\begin{array}{l}\text { HCAECs, HCASMCs, } \\
\text { hESC-derived EC, hESCs, } \\
\text { HPAECs, HUVECs, PBMC }\end{array}$ & {$[103-105,107]$} \\
\hline
\end{tabular}

ANRIL antisense ncRNA in the INK4 locus, APPAT atherosclerotic plaque pathogenesis-associated transcript, $B A N C R$ BRAF-regulated lncRNA 1, CASMCs human coronary artery vascular smooth muscle cells, CECs circulating endothelial cells, CHROME cholesterol homeostasis regulator of microRNA expression, EA.hy926 human umbilical vein cell line, ECs endothelial cells, EPCs endothelial progenitor cells, FENDRR Forkhead box protein F1 (FOXF1) adjacent non-coding developmental regulatory RNA, GAS5 growth arrest-specific 5, iPSC induced pluripotent stem cell, H19 imprinted maternally expressed transcript, HAECs human aortic endothelial cells, HASMCs human aortic smooth muscle cells, HA-VSMCs human aorta vascular smooth muscle cells, HCAECs human coronary artery endothelial cells, HCASMCs human coronary artery smooth muscle cells, HCMEC-C cardiac microvasculature, $h C o A E C s$ human coronary artery endothelial cells, HCSMs human coronary artery smooth muscle, $h E S C$ human embryonic stem cells, HMEC human microvascular endothelial cell line, HMVECs human microvascular endothelial cells,HMVEC-L lung microvasculature, HOTAIR HOX transcript antisense RNA, HOTTIP HOXA transcript at the distal tip, HPAECs human pulmonary artery endothelial cells, HSVSMCs human saphenous vein smooth muscle cells, HSVECs human saphenous vein endothelial cells, HPASMCs human pulmonary artery smooth muscle cells, HuAoVSMCs human aortic vascular smooth muscle cells, HUVECs human umbilical vein endothelial cells, HUVE-12 human umbilical vein endothelial cells-12, HYMAI hydatidiform mole-associated and imprinted transcript, linc-p21 long intergenic non-coding RNA p21, IncRNA long non-coding RNA, MALAT1 metastasis-associated lung adenocarcinoma transcript 1, MIAT myocardial infarction-associated transcript, MonoMac monocytic cell line, NEXN-AS1 NEXN antisense RNA $1, N O$ nitric oxide, $o x-L D L$ oxidised low-density lipoprotein, $P B M C s$ peripheral blood mononuclear cells, $R N C R 3$ retinal non-coding RNA3, SENCR smooth muscle and endothelial enriched lncRNA, SMILR smooth muscle-induced lncRNA enhances replication, SNHG6 small nucleolar RNA host gene 6, T/G HA-VSMC human aortic vascular smooth muscle cell line, THP-1 human leukaemic monocyte, U937 human mononuclear cells, VSMCs vascular smooth muscle cells, Zfas 1 ZNFX1 antisense RNA 1, $\uparrow$ indicates upregulated, $\downarrow$ indicates downregulated

while decreasing the level of insulin-like growth factor 2 (IGF2) transcript; therefore, it was proposed that homocysteine may promote proliferation by inducing hypomethylation of the sixth CCCTC-binding factor $(C T F C)$ binding sites located upstream of $H 19$ [37]. In case of ECs, $H 19$ may facilitate cell proliferation while impeding cell senescence and inflammatory activation by inhibition of signal transducer and activator of transcription (STAT) 3 signalling [28]. Recently, published research has shed light on the mechanisms of action by which $H 19$ may regulate cell function. Pan [30] has shown that overexpression of $H 19$ in both VSMCs and human umbilical vein ECs (HUVECs) resulted in increased levels of $\mathrm{p} 38$ and $\mathrm{p} 65$, suggesting possible facilitation of proliferation and apoptosis suppression by the mitogen-activated protein kinase (MAPK) and nuclear factor (NF)-KB pathway [30]. Sun et al. [38] found that $H 19$ may act as a competing endogenous RNA (ceRNA) through an interaction with let-7a, which results in the promotion of cyclin D1 expression and at the cellular level also leads to VSMC proliferation [38]. Additionally, Zhang et al. [32] indicated a role for $\mathrm{H} 19$ in modulating the $\mathrm{Wnt} / \beta$-catenin signalling pathway in oxidised low-density lipoprotein (oxLDL)-treated human aorta VSMCs (HA-VSMCs). H19 may promote proliferation and decrease apoptosis by sponging
microRNA (miR)-148b to enhance Wnt family member 1 (Wntl) expression [32]. In another study, Huang et al. [39] showed that the acid phosphatase 5 (ACP5) gene could be a potential target of H19. Overexpression of H19 in HUVECs and VSMCs resulted in increased ACP5 levels, facilitated cell proliferation and inhibited apoptosis [39]. Song et al. [40] showed that astragaloside IV might affect autophagy by modulating $H 19$ expression. This pharmacological stimulant elicited an increased expression of $H 19$, phosphorylated ERK1/2 nuclear phosphatase (p-ERK1/2), and phosphorylated mammalian target of rapamycin (p-mTOR) while inhibiting dual specificity protein phosphatase 5 (DUSP5) expression, which resulted in reduced mineralization and autophagy in VSMCs [40].

\subsubsection{ANRIL}

Antisense ncRNA in the INK4 locus (ANRIL) is an lncRNA derived from the chromosome 9p21 region [41], which comprises several single nucleotide polymorphisms (SNPs) associated with an increased risk of CAD and atherosclerosis development [42]. Furthermore, some of the identified SNPs lay within the ANRIL gene sequence (see $\mathrm{Hu}$ et al. [43] and $\mathrm{Xie}$ et al. [44]). The data gathered so far have suggested that 


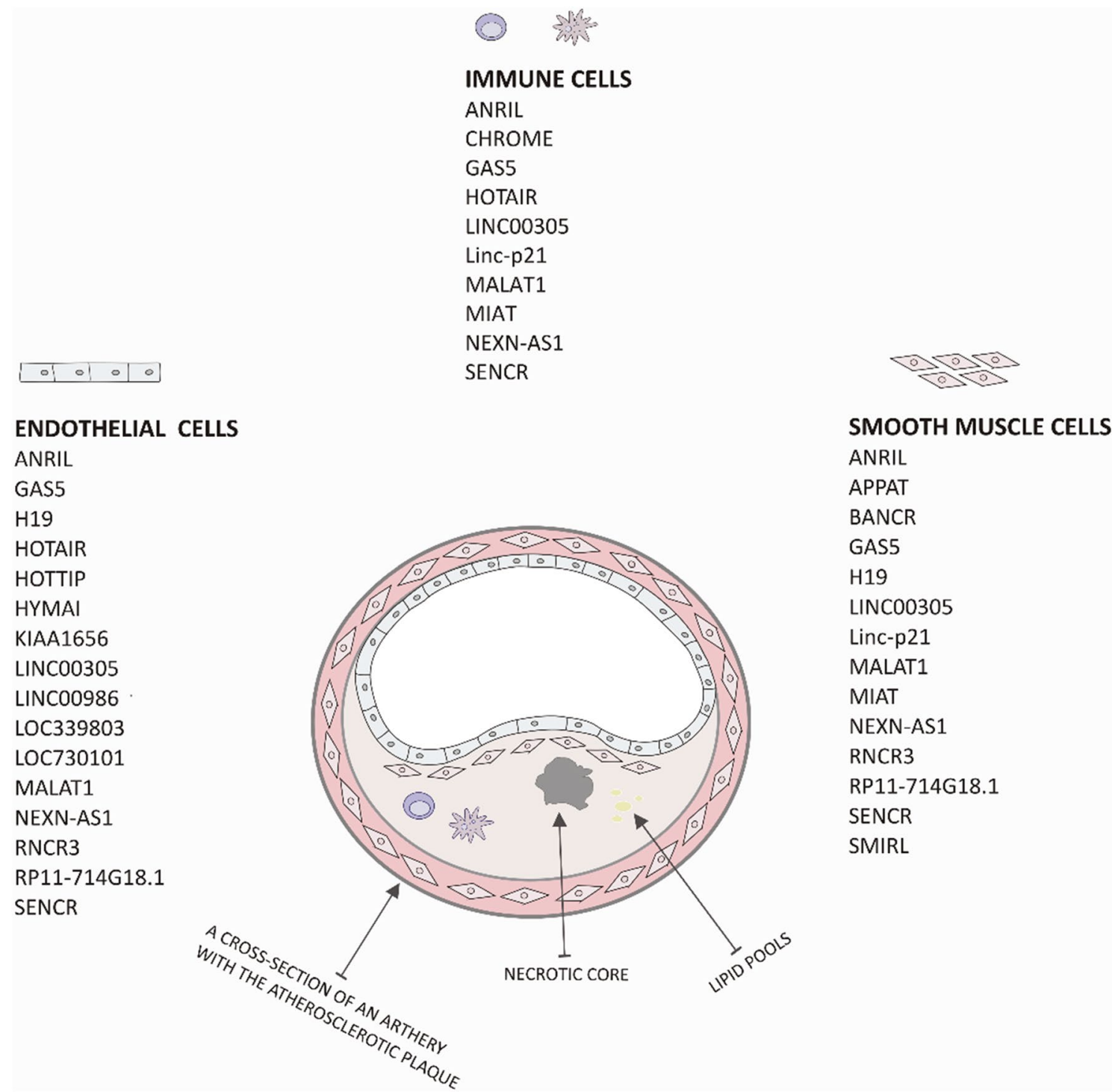

Fig. 1 List of long non-coding RNAs (lncRNAs) with aberrant expression in the atherosclerotic plaque reported in this review. lncRNAs are divided according to their association with immune cells, endothelial cells and smooth muscle cells. ANRIL antisense ncRNA in the INK4 locus, APPAT atherosclerotic plaque pathogenesisassociated transcript, BANCR BRAF-regulated lncRNA 1, CHROME cholesterol homeostasis regulator of microRNA expression, GAS5 growth arrest-specific 5, H19 imprinted maternally expressed tran-

there are many linear or even circular transcripts of ANRIL. Importantly, linear ANRIL is connected with pro-atherogenic cell function while circular ANRIL has shown the opposite, atheroprotective effects; moreover, CAD risk SNPs up- and downregulate the expression levels of linear and circular ANRIL transcripts [45], respectively. A more detailed summary of the current knowledge regarding the association of ANRIL with genetic polymorphism of the 9p21 locus in the context of atherosclerosis can be found in the review article by Holdt et al. [45]. Therefore, we focused on the script, HOTAIR HOX transcript antisense RNA, HOTTIP HOXA transcript at the distal tip, HYMAI hydatidiform mole-associated and imprinted transcript, Linc-p21 long intergenic non-coding RNA p21, MALAT1 metastasis-associated lung adenocarcinoma transcript 1, MIAT myocardial infarction-associated transcript, NEXN-AS1 NEXN antisense RNA 1, RNCR3 retinal non-coding RNA3, SENCR smooth muscle and endothelial enriched lncRNA, SMILR smooth muscleinduced lncRNA enhances replication

relevance of ANRIL for cardiovascular cell function because its expression was detected in ECs, VSMCs and different immune cells $[46,47]$. Researchers have shown that ANRIL splicing variants could affect the expression of distinct genes involved in pathways linked with atherosclerosis [48] and potentially this regulation could be exerted by cis- or transregulatory mechanisms (for detailed review, see Chi et al. [49] and Aarabi et al. [50]). Stress factors could elicit different expression patterns of ANRIL transcripts. For example, stimulation of ECs by tumour necrosis factor (TNF)- $\alpha$ or 
ox-LDL cholesterol led to upregulation of the full-length ANRIL transcript (NR_003529) but downregulation of the $A N R I L$ transcript $D Q 485454$. Interestingly, the $D Q 485454$ transcript was most abundant in EC lines and decreased in the coronary artery of CAD patients. Gain-and loss-offunction experiments revealed that ANRIL DQ485454 affects monocyte adhesion to ECs and transmigration across ECs along with EC migration, probably via regulation of the expression of CLIP1, EZR, and LYVE1 [51]. Guo et al. [52] have shown that human coronary artery ECs (HCAECs) viability, survival and apoptosis, and the production of proteins specific for the epithelial-mesenchymal transition along with the release of inflammatory factors and vascular-protective factors might be regulated by the ANRIL/miR-181b/ $\mathrm{NF}-\kappa \mathrm{B}$ signalling pathway [52]. Zhou et al. [53] previously demonstrated the upregulation of interleukin $(I L)-6 / I L-8$ expression in TNF- $\alpha$-stimulated ECs through ANRIL binding to the transcriptional factor Yin Yang 1 (YY1). Another investigation revealed that distinct ANRIL splicing variants can affect the expression of atherosclerosis-related genes in VSMCs [54]. For instance, ANRIL affects VSMC proliferation probably via the regulation of cyclin-dependent kinase (CDK) inhibitor 2A/B expression [55]. The circular transcript of ANRIL (circANRIL) is claimed to exert atheroprotective function through binding to pescadillo homologue 1 (PES1), which results in an impairment of pre-ribosomal RNA (rRNA) maturation and an induction of nucleolar stress along with p53 activation. In line with that, overexpression of circANRIL in VSMCs and macrophages led to an induction of apoptosis and a reduction in proliferation, which was accompanied by increased numbers of nucleoli and an accumulation of pre-rRNAs in these cells [56]. Several studies have established the expression of both circular and linear ANRIL transcripts in APs and human blood [56-59], indicating the importance of an expression pattern of linear and circular ANRIL transcripts in atherosclerosis development [45].

\subsubsection{GAS5}

Growth arrest-specific 5 (GAS5) has gained attention as an IncRNA that could potentially be utilised as a diagnostic biomarker for atherosclerosis. Its gene is located on chromosome 1 , and the ins/del polymorphism (rs1452042) of the promoter region is linked to the risk of disease development [60]. Moreover, the level of GAS5 was upregulated in APs $[61,62]$ and plasma of atherosclerosis patients [63], while it was downregulated in the plasma [64] or serum of CAD patients [65]. This IncRNA is involved both in the regulation of vascular cell function in vitro, such as cell activation, viability, apoptosis, proliferation, migration, tube formation, vasoconstrictor production and phenotypic switching, and in the response to stress conditions such as hypoxia or $\mathrm{H}_{2} \mathrm{O}_{2}$ stimulation [66]. Of note, GAS5 could participate in cell communication, being transmitted in exosomes [66, 67]. The molecular mechanism underlying GAS5 function in HUVECs and VSMCs may be linked to $\beta$-catenin signalling, as GAS5 was proved to interact with $\beta$-catenin protein and affect its nuclear translocation [66]. In a subsequent study, Yin et al. [64] showed that in HCAEC GAS5 might be engaged in the mTOR signalling pathway through inhibition of its activation. Interestingly, ox-LDL stimulation of human leukaemic monocyte (THP-1)-derived macrophages triggers elevated expression of GAS5. A possible model describes GAS5 acting via sponging miR-221, which results in the production of pro-inflammatory molecules and matrix metalloproteinase (MMP) secretion by macrophages [62]. Recently, Yang et al. [68] have shown that GAS5 is also involved in other inflammatory pathways activated in Porphyromonas gingivalis-stimulated macrophages. Another study found that ox-LDL-treated macrophages release exosomes enriched in GAS5, which could be taken up by HUVECs, subsequently leading to increased apoptosis of the ECs [67]. Liang et al. [63] reported that GAS5 interaction with miR-26a could contribute to ox-LDL-induced apoptosis and defective autophagy in human aortic ECs (HAEC). Previously, regulation of GAS5 along with other ncRNA expression was also observed in ECs in vitro during angiogenesis promoted by isoprenaline-a synthetic catecholamine [69]

\subsubsection{MIAT}

MI-associated transcript (MIAT) was discovered and characterised as a result of investigations concerning SNP association with heart diseases in the Japanese population [70, 71]. Further studies have shown that MIAT was upregulated in APs [24] as well as in the serum of patients suffering from symptoms of vulnerable APs [72]. In a recently published article, Zhong et al. [73] shed light on a role of MIAT in atherosclerosis, indicating that elevated expression of MIAT was found in atherosclerosis patients' serum as well as in ox-LDL-treated smooth muscle cells and mononuclear cells in vitro, whereas miR-181b exhibited the opposite expression pattern [73]. Functional assays have shown that MIAT augmented the proliferation of, while hindering apoptosis in, HA-VSMCs and human mononuclear cells (U937) by sponging miR-181b, resulting in enhanced STAT3 expression [73].

\subsubsection{CHROME}

lncRNA cholesterol homeostasis regulator of miR expression $(C H R O M E)$ is a primate-specific lncRNA that exerts a role in cholesterol homeostasis in humans. This lncRNA is transcribed from a locus situated on chromosome 2 and has seven splice variants that contain Alu transposable repeat elements. Elevated CHROME expression was found in infiltrating inflammatory cells in the APs and plasma of patients 
with CAD. Subsequent analysis has shown that in THP-1-derived macrophages, CHROME expression may be regulated by the sterol-activated liver $\mathrm{X}$ receptor transcription factor LXR, and its increased level was elicited by stimulation with acetylated LDL. Moreover, CHROME may play a role in the cholesterol efflux pathway in macrophages via interactions with miR-27b, miR-33a, miR-33b and miR-128. Notably, CHROME silencing led to a decreased level of ATP-binding cassette transporter A1 (ABCA1) protein, which regulates cellular cholesterol homeostasis [74].

\subsubsection{SMILR}

The expression of smooth muscle-induced lncRNA enhances replication (SMILR) was initially found in VSMCs stimulated with IL- $1 \alpha$ or platelet-derived growth factor (PDGF). The genomic localisation of this lncRNA is in proximity to the hyaluronan synthase 2 (HAS2). Of note, elevated SMILR levels were observed in unstable APs as well as in the plasma of patients suffering from inflammation where SMILR levels exhibited a positive correlation with C-reactive protein levels. VSMCs in vitro were able to release SMILR into the medium but, interestingly, it was not detected in the exosomes or microvesicles. The subsequent functional assays have shown that SMILR overexpression leads to increased proliferation of VSMCs, and this effect may be exerted by the regulation of HAS2 expression [75]. It was further reported that increased SMILR expression is strongly associated with a synthetic phenotype of VSMCs in vitro [76].

\subsubsection{LINC00305}

Long intergenic ncRNA 00305 (LINC00305) was found to be associated with atherosclerosis as a result of the genomewide association study (GWAS) that had uncovered two disease-associated SNPs, rs2850711 and rs2676671, located in an intron of the LINC00305 gene. Moreover, APs, along with CD14-positive cells from atherosclerosis patients, exhibited an increased expression level of LINC00305. A subsequent functional investigation revealed that LINC00305 overexpression facilitates inflammation THP-1 cells by associating with lipocalin-1 interacting membrane receptor (LIMR), thus enhancing the LIMR-AHRR (aryl-hydrocarbon receptor repressor) interaction and AHRR protein expression along with its nuclear localisation, which results in inhibition of AHR signalling and NF- $\mathrm{\kappa B}$ activation. At the cellular level, overexpression of LINCO0305 may promote switching from a contractile to a synthetic phenotype in human aortic smooth muscle cells (HASMCs) co-cultured with THP-1 cells [77]. Another study demonstrated that LINC00305 plays a role during EC impairment, promoting apoptosis by acting as a miR-139 sponge. In hypoxia-induced HUVECs, LINC00305 upregulation resulted in augmented apoptosis and suppressed proliferation [78].

\subsubsection{RNCR3}

In APs as well as in ox-LDL-treated ECs and VSMCs, retinal ncRNA3 (RNCR3) expression levels are significantly increased, which could be a part of an atheroprotective mechanism. Of interest, exosomes could transfer RNCR3 between ECs and VSMCs. This IncRNA plays a role in promoting proliferation and migration while suppressing apoptosis in both cell lines. It is possible that RNCR3 may exert its biological function as a ceRNA in the Kruppel-like factor $2(\mathrm{KLF} 2) / \mathrm{miR}-185-5 \mathrm{p}$ regulatory network by sponging miR-185-5p to regulate the KLF2 gene expression level [79].

\subsubsection{BANCR}

$B R A F$-regulated lncRNA 1 (BANCR) was discovered in melanoma cells as a transcript regulating the expression of genes involved in cell migration [80]. The AP tissues, along with proliferating VSMCs, exhibited upregulated $B A N C R$ expression. Further functional assays have revealed that elevated BANCR expression in VSMCs led to increased cell proliferation and migration, probably via modulation of c-Jun N-terminal kinase (JNK) expression [81].

\subsubsection{HOTTIP}

HOXA transcript at the distal tip (HOTTIP) is a $3764 \mathrm{bp}$ lncRNA derived from the HOTTIP gene located near HOXA13 [82]. Recently, scientists discovered that HOTTIP expression levels were upregulated in CAD tissue as well as in ECs stimulated by TNF- $\alpha$ or PDGF-BB in vitro. Subsequent gain- and loss-of-function assays have revealed possible promotion of EC proliferation and migration through the $\mathrm{Wnt} / \beta$-catenin pathway activation [83].

\subsubsection{LINC00968}

Long intergenic non-protein coding RNA 968 (LINC00968) has emerged as a novel atherosclerosis-associated lncRNA since Wang et al. [84] found its upregulated expression in atherosclerosis tissue obtained from CAD patients. Of note, ox-LDL treatment of ECs leads to increased expression of LINC00968 and inhibited expression of miR-9-3. Interestingly, a decreased level of miR-9-3 was also found in CAD patient samples. Further functional analysis has shown that elevated expression of LINC00968 may augment the proliferation and migration of ECs through modulation of miR9-3p expression [84]. 


\subsubsection{SNHG6, Zfas1, HYMAI, LOC730101, KIAA1656 and LOC339803}

To date, the contribution of small nucleolar RNA host gene 6 (SNHG6) and ZNFX1 antisense RNA 1 (Zfas1) to AP development remains unknown [61]. Recently, bioinformatics analysis has showed co-expression of Zfas 1 with 358 mRNAs, which are dysregulated in atherosclerosis progression, indicating its potential function in atherosclerosis [7]. Hydatidiform mole-associated and imprinted transcript (HYMAI), lncRNA LOC730101, lncRNA KIAA1656 and lncRNA LOC339803 are other examples of newly identified lncRNAs in APs. It has been shown that they are upregulated in primary and restenosis plaques, and their expression in HUVECs is modulated under hypoxic conditions; however, the exact molecular mechanisms require further characterisation [85].

\subsection{LncRNAs Downregulated in APs in Comparison with Healthy Tissue}

\subsubsection{MALAT1}

Metastasis-associated lung adenocarcinoma transcript 1 (MALAT1) was identified in lung cancer cells as well as various healthy tissues [86]. In the AP, the MALAT1 expression level was downregulated $[24,87]$. The same expression pattern, as mentioned earlier, was found in both primary and restenotic APs [85]. Of note, in the blood of CAD patients and endothelial progenitor cells (EPCs), MALAT1 expression was increased [88]. The previous analysis revealed that higher expression levels of MALAT1 in plaques might be correlated with plaque stability and good prognosis, suggesting that this lncRNA could be used as a predictive marker of atherosclerosis progression [87]. Interestingly, microvascular, venous and arterial ECs in vitro exhibited high expression of MALAT1 [89]. Further functional assays showed that at the cellular level, MALATI promoted the proliferation but decreased the migration of ECs. Several studies have shown its upregulated expression in response to different stressful stimuli, e.g. a hypoxic condition in which hypoxia-inducible factor $1 \alpha(\mathrm{HIF} 1 \alpha)$ [90] causes elevated expression of MALAT1 in ECs [89]. During oxidative stress in ECs, MALATl exerts a protective function, attenuating cell death and apoptosis. Mechanistically, MALATl contributes to the downregulation of Kelch-like ECH-associated protein 1 (Keap1), thereby indirectly activating the nuclear factor erythroid 2-related factor 2 (Nrf2) signalling pathway [91]. In ox-LDL-stimulated ECs, MALAT1 reduces apoptosis and pro-inflammatory cytokine release probably by acting as a ceRNA, and, to date, scientists have found two possible molecular mechanisms. Tang et al. [92] indicated that MALATl interacts with miR-22-3p, leading to the upregulation of $\mathrm{C}-\mathrm{X}-\mathrm{C}$ chemokine receptor type 2 (CXCR2) and $\mathrm{RAC}-\alpha$ serine/threonine-protein kinase $(A K T)$ expression, while, more recently, Li et al. [93] found that MALAT1 may bind to miR-155, leading to an increase in the suppressor of cytokine signalling 1 (SOCS1), which results in JAKSTAT signalling pathway repression. In contrast, the upregulation of MALAT1 induced by high glucose levels in ECs was linked to increased expression of inflammatory mediators [94] and resulted in the promotion of pyroptosis partly by sponging miR-22, which led to the increased expression of the NLRP3 inflammasome [95]. All of the aforementioned stress agents can induce endothelial-to-mesenchymal transition (endMT), a process that commonly appears in APs [96]. In ox-LDL-stimulated HUVECs, MALATI could affect endMT by the activation of the $\mathrm{Wnt} / \beta$-catenin axis [97], while in transforming growth factor (TGF)- $\beta 1$-stimulated human circulating EPCs by the regulation of the miR-145TGFBR2/SMAD3 pathway [98]. In macrophages, ox-LDL or lipopolysaccharide (LPS) treatment could induce the elevated expression of MALAT1 [99, 100]. Dissecting the function of MALAT1 during ox-LDL stimulation showed that its interaction with $\beta$-catenin led to the promotion of $C D 36$ transcription, which augments lipid uptake in macrophages via scavenger receptors [100]. In response to LPS stress stimuli, MALATl inhibits the binding of NF- $\mathrm{KB}$ to target promoters leading to the attenuated production of TNF- $\alpha$ and IL- 6 through interaction with NF- $\kappa B$ subunits p65 and p50 [99]. In pumonary smooth muscle cells, MALAT1 augments proliferation by affecting CDK inhibitor expression but also facilitates migration. Similar to what has been reported for ECs, hypoxia is a factor that results in the upregulation of MALAT1, and HIF1 $\alpha$ may be engaged in the modulation of MALAT1 expression [101], while extracellular matrix stiffness is associated with decreased levels of MALAT1 [102].

\subsubsection{SENCR}

Smooth muscle and endothelial enriched lncRNA (SENCR) is transcribed from the antisense strand of the first intron of a protein-coding gene called Friend leukaemia virus Integration 1 and exists in two isoforms: SENCR_VI (a fulllength transcript) and $S E N C R \_V 2$ (an alternative splice variant). Interestingly, SENCR was expressed in endothelial and smooth muscle cells with solely cytoplasmic spatial distribution and therefore may play its biological role by acting in trans. Subsequent investigation revealed its role in maintaining the contractile phenotype of smooth muscle cells, probably via the regulation of myocardin (MYOCD), a contractile and pro-migratory gene, expression; nevertheless, the exact molecular mechanism of action remains elusive [103]. More recently, scientists have shown that SENCR could play a role in EC development and facilitates 
the proliferation, migration and angiogenesis of HUVECs. Additionally, SENCR expression levels were decreased in patients with EC dysfunction and atherosclerotic vascular disease [104]. Lyu et al. [105] demonstrated elevated expression of SENCR in vitro in human ECs subjected to laminar stress, indicating its role in maintaining EC membrane integrity via stabilization of cell adherens junctions. Binding of SENCR to a non-canonical RNA binding domain of cytoskeletal-associated protein 4 (CKAP4) entails promoting an interaction of vascular endothelial (VE)-catenin with p120-cadherin instead of CKAP4, thereby indirectly enabling VE-catenin placement at the adherens junctions of ECs [105]. While SENCR gene polymorphism does not constitute a potential genetic risk factor for CAD [106], its altered expression in circulating ECs (CECs) and monocytes is associated with early-onset CAD (EOCAD); therefore, it could serve as an endothelial dysfunction biomarker [107]. Downregulation of SENCR in CECs and upregulation in monocytes along with increased surface/intracellular levels of CD146 in CECs and CD14 in monocytes were found in blood samples of EOCAD patients. Further analysis showed a positive correlation between SENCR expression and the surface/intracellular level of CD14 protein in monocytes. Theoretically, there may be an interaction between sequences localised in the second exon of SENCR and the 5' untranslated region of $C D 14$ (transcript variant 1 or 3) mRNA, indicating that SENCR could exert a role in stabilizing mRNAs or enhancing $C D 14$ transcription in monocytes [107].

\subsection{3 linc-p21}

Long intergenic ncRNA p21 (linc-p2l) is situated $15 \mathrm{~kb}$ upstream of the CDKN1A gene-encoding protein $\mathrm{p} 21$ that regulates the cell cycle [108]. Structurally, it is a singleexon IncRNA, which exists in two isoforms containing two inverted repeat Alu elements that can form secondary structures [109]. Various studies have confirmed the significance of linc-p21 for development of CVDs. It was shown that polymorphism of linc-p21 is associated with risk of CAD and MI among the Chinese Han population [110] and its transcript level was decreased in peripheral blood mononuclear cells (PBMCs) obtained from CAD patients [111]. Moreover, the expression of linc-p21 was found to be downregulated in APs [111, 112]. Functional analysis has shown that linc-p21 promotes apoptosis and reduces the proliferation of VSMCs $[111,113]$. At the molecular level, linc-p21 may modulate p53 activity by interacting with mouse double minute 2 (MDM2), resulting in the release of $\mathrm{p} 53$ from MDM2 and $\mathrm{p} 53$ binding to p300 [111]. Recently Hu et al. [113] showed that linc-p21 could exert a biological role in VSMCs through activation of the TGF- $\beta 1$ axis.

\subsubsection{HOTAIR}

HOX transcript antisense RNA (HOTAIR) is an lncRNA derived from the transcription of the antisense strand of the HoxC gene, located on chromosome 12 [114]. ECs isolated from APs had a decreased level of HOTAIR transcript [115]. Previous studies demonstrated elevated expression of thymic stromal lymphopoietin (TSLP) in APs, especially in layers containing smooth muscle cells [116]. Of note, Peng et al. [115] found a positive correlation between the serum level of TSLP and HOTAIR expression in the ECs of atherosclerosis patients and proved that TSLP regulates HOTAIR transcription via the PI3K (phosphoinositide 3-kinase)/AKT-IRF1 (interferon regulatory factor 1) pathway. Further functional assays have shown the role of HOTAIR in a protection against ox-LDL-induced injury, promoting proliferation and migration, and suppressing apoptosis in ECs in vitro [115]. Recently, the function of HOTAIR was also investigated in macrophages, showing that in ox-LDL-treated THP-1 cells, its overexpression led to increase in apoptosis, di-ox-LDL uptake, oxidative stress and inflammation. At the molecular level, HOTAIR may exert its role as a ceRNA for miR-330-5p [117]. Some research indicates that HOTAIR could be a potential biomarker for atherosclerosis. Pang et al. [118] found that HOTAIR expression was downregulated in lymphocytes derived from atherosclerosis patients, while Avazpour et al. [119] demonstrated the opposite result: elevated HOTAIR expression in PBMCs from patients suffering from severe coronary artery stenosis.

\subsubsection{NEXN-AS1}

NEXN antisense RNA 1 (NEXN-AS1) has been shown to play a role in atherosclerosis since the discovery that this lncRNA along with the transcript of $N E X N$ has decreased levels in human APs. Both the NEXN-ASI and NEXN genes share a location on chromosome 1 and even have a partially overlapping sequence [120]. Previously, NEXN gene polymorphism was found to be linked with susceptibility to CAD in Han Chinese [121]; furthermore, CAD patients exhibited decreased levels of nexilin F-actin binding protein (NEXN) in the blood [120]. The comparison of NEXN-AS1 and $N E X N$ expression patterns between three different stages of plaque development has shown that in the early plaque (types I-III according to the AHA classification) NEXNAS1 and NEXN expression levels were higher than those in advanced plaques (types IV-VIII). Among advanced plaque types, higher levels were found in advanced stable plaques (types VII and VIII) than in advanced vulnerable plaques (types IV-VI). NEXN-ASI may upregulate NEXN expression in cultured vascular ECs via interaction with the 
chromatin remodeller BAZ1A and NEXN gene 5'-flanking region. Other functional assays showed that elevated expression of NEXN-AS1 in monocytes in vitro inhibited monocyte adhesion to vascular ECs, while in VSMCs this phenomenon resulted in reduced migration. In HUVECs, enhanced expression of NEXN-AS1 suppressed LPS-induced expression of adhesion molecules, cytokines and extracellular matrix-degrading enzymes. Moreover, $N E X N-A S 1$ was shown to exert a role on monocyte chemoattractant protein-1 (MCP1), TNF- $\alpha$, and IL-6 expression though NEXN. Investigations of specific mechanisms revealed that NEXN-ASI and NEXN might suppress the TLR4-NFKB signalling pathway in HUVECs [120].

\subsubsection{RP11-714G18.1}

lncRNA RP11-714G18.1 is a newly identified lncRNA, which shows downregulated expression in the APs. Its genomic locus is located adjacent to the protein-coding gene for lipoprotein-related receptor 2 binding protein (LRP2BP) on chromosome 4. Moreover, these two genes have opposite transcription directions and share a conserved 89 bp sequence; therefore, RP11-71418.1 could potentially interact with $L R P 2 B P$. Interestingly, further investigation implied that overexpression of RP11-71418.1 and LRP2BP may suppress cell migration in HA-VSMCs and HUVECs partly via downregulation of $M M P 1$ expression. The results of gain-of-function experiments demonstrated that at a cellular level RP11-71418.1 also inhibits cell adhesion and tube formation and promotes nitric oxide production in HUVECs while suppressing apoptosis and augmenting proliferation in HA-VSMCs [122].

\subsubsection{APPAT}

The intergenic lncRNA-AP pathogenesis-associated transcript (APPAT) was first identified in human blood. Importantly, in the AP, it exhibited downregulated expression and was stable in the bloodstream; therefore, a change in the APPAT expression pattern could potentially serve as a biomarker reflecting disease progression. The spatial distribution of APPAT within the human coronary artery was detected mainly in the cytoplasm of tunica media contractile smooth muscle cells, suggesting that its biological function may be exerted by acting as a ceRNA for miR. Subsequent investigation has shown that miR-647 could be a potential target for APPAT as the two molecules exhibited opposite expression patterns in arteriostenosis samples [123].

\subsubsection{FENDRR}

Forkhead box protein F1 (FOXF1) adjacent non-coding developmental regulatory RNA (FENDRR) was first reported as an lncRNA that plays role during heart and body wall development in mice. Nevertheless, there was no clear evidence indicating FENDRR involvement in CVD [124] until recently conducted research showed downregulation of this lncRNA in an AP [112]. The exact role of FENDRR in atherosclerosis development requires further investigation.

\section{Future Perspective and Conclusions}

In summary, recent studies have uncovered the altered expression of many lncRNAs in APs. They have indicated that these transcripts participate in the regulation of a broad spectrum of cellular processes; however, for most of them, the molecular mode of action remains elusive. Further exploration of the functions of atherosclerosis-related lncRNAs would require a focus on differently expressed splice variants and genetic polymorphisms alongside single-cell expression analysis. To date, multiple lines of evidence have implicated lncRNAs as potential targets for detecting initiation and progression as well as for treating of atherosclerosis and predicting outcomes; therefore, continuing efforts in this area should remain the highest priority in the coming years. In this context, there is a pressing need to establish a standardised experimental pipeline and validation of lncRNAs as possible relevant biomarkers for CVD that would enable the translation of gathered findings into clinical practice.

\section{Compliance with Ethical Standards}

Conflict of Interest Weronika Kraczkowska Paweł Piotr Jagodziński declare they have no conflicts of interest that are directly relevant to the content of this review.

Funding No financial support was received in relation to this article.

Open Access This article is distributed under the terms of the Creative Commons Attribution-NonCommercial 4.0 International License (http://creativecommons.org/licenses/by-nc/4.0/), which permits any noncommercial use, distribution, and reproduction in any medium, provided you give appropriate credit to the original author(s) and the source, provide a link to the Creative Commons license, and indicate if changes were made.

\section{References}

1. Herrington W, Lacey B, Sherliker P, Armitage J, Lewington $\mathrm{S}$. Epidemiology of atherosclerosis and the potential to reduce the global burden of atherothrombotic disease. Circ Res. 2016;118:535-46.

2. Kovacic S, Bakran M. Genetic susceptibility to atherosclerosis. Stroke Res Treat. 2012;2012:362941. https://doi. org/10.1155/2012/362941.

3. Lusis AJ. Atherosclerosis. Nature. 2000;407:233-41. 
4. Tuttolomondo A, Di Raimondo D, Pecoraro R, Arnao V, Pinto A, Licata G. Atherosclerosis as an inflammatory disease. Curr Pharm Des. 2012;18:4266-88.

5. Ross R, Glomset J, Harker L. Response to injury and atherogenesis. Am J Pathol. 1977;86:675-84.

6. Stary HC, Chandler AB, Dinsmore RE, Fuster V, Glagov S, Insull $\mathrm{W}$, et al. A definition of advanced types of atherosclerotic lesions and a histological classification of atherosclerosis: a report from the Committee on Vascular Lesions of the Council on Arteriosclerosis, American Heart Association. Circulation. 1995;92:1355-74.

7. Wang C-H, Shi H-H, Chen L-H, Li X-L, Cao G-L, Hu X-F. Identification of key lncRNAs associated with atherosclerosis progression based on public datasets. Front Genet. 2019;10:123.

8. Ma L, Cao J, Liu L, Du Q, Li Z, Zou D, et al. LncBook: a curated knowledgebase of human long non-coding RNAs. Nucleic Acids Res. 2019;47:D128-34.

9. Xu Y, Wu W, Han Q, Wang Y, Li C, Zhang P, et al. New insights into the interplay between non-coding RNAs and RNA-binding protein HnRNPK in regulating cellular functions. Cells. 2019;8:62. https://doi.org/10.3390/cells8010062.

10. Deniz E, Erman B. Long noncoding RNA (lincRNA), a new paradigm in gene expression control. Funct Integr Genomics. 2017;17:135-43.

11. Knauss JL, Sun T. Regulatory mechanisms of long noncoding RNAs in vertebrate central nervous system development and function. Neuroscience. 2013;235:200-14.

12. van Heesch $S$, van Iterson M, Jacobi J, Boymans S, Essers PB, de Bruijn E, et al. Extensive localization of long noncoding RNAs to the cytosol and mono- and polyribosomal complexes. Genome Biol. 2014;15:R6.

13. Dorn GW. LIPCAR: a mitochondrial lnc in the noncoding RNA chain? Circ Res. 2014;114:1548-50.

14. Kumarswamy R, Bauters C, Volkmann I, Maury F, Fetisch J, Holzmann A, et al. Circulating long noncoding RNA, LIPCAR, predicts survival in patients with heart failure. Circ Res. 2014;114:1569-75.

15. Johnsson P, Lipovich L, Grandér D, Morris KV. Evolutionary conservation of long noncoding RNAs; sequence, structure, function. Biochim Biophys Acta. 2014;1840:1063-71.

16. Wang KC, Chang HY. Molecular mechanisms of long noncoding RNAs. Mol Cell. 2011;43:904-14.

17. Amin N, McGrath A, Chen Y-PP. Evaluation of deep learning in non-coding RNA classification. Nat Mach Intell. 2019;1:246-56.

18. Ransohoff JD, Wei Y, Khavari PA. The functions and unique features of long intergenic non-coding RNA. Nat Rev Mol Cell Biol. 2018;19:143-57.

19. Delás MJ, Hannon GJ. lncRNAs in development and disease: from functions to mechanisms. Open Biol. 2017;7:170121. https ://doi.org/10.1098/rsob.170121.

20. Sallam T, Sandhu J, Tontonoz P. Long noncoding RNA discovery in cardiovascular disease: decoding form to function. Circ Res. 2018;122:155-66.

21. Casamassimi A, Federico A, Rienzo M, Esposito S, Ciccodicola A. Transcriptome profiling in human diseases: new advances and perspectives. Int J Mol Sci. 2017;18:1652.

22. Sluimer JC, Kisters N, Cleutjens KB, Volger OL, Horrevoets AJ, van den Akker LH, et al. Dead or alive: gene expression profiles of advanced atherosclerotic plaques from autopsy and surgery. Physiol Genomics. 2007;30:335-41.

23. Perisic L, Aldi S, Sun Y, Folkersen L, Razuvaev A, Roy J, et al. Gene expression signatures, pathways and networks in carotid atherosclerosis. J Intern Med. 2016;279:293-308.

24. Arslan S, Berkan Ö, Lalem T, Özbilüm N, Göksel S, Korkmaz Ö, et al. Long non-coding RNAs in the atherosclerotic plaque. Atherosclerosis. 2017;266:176-81.
25. Bonetti PO, Lerman LO, Lerman A. Endothelial dysfunction: a marker of atherosclerotic risk. Arterioscler Thromb Vasc Biol. 2003;23:168-75.

26. Gibb EA, Brown CJ, Lam WL. The functional role of long noncoding RNA in human carcinomas. Mol Cancer. 2011;10:38.

27. Han DK, Khaing ZZ, Pollock RA, Haudenschild CC, Liau G. $\mathrm{H} 19$, a marker of developmental transition, is reexpressed in human atherosclerotic plaques and is regulated by the insulin family of growth factors in cultured rabbit smooth muscle cells. J Clin Invest. 1996;97:1276-85.

28. Hofmann P, Sommer J, Theodorou K, Kirchhof L, Fischer A, $\mathrm{Li} \mathrm{Y}$, et al. Long non-coding RNA H19 regulates endothelial cell aging via inhibition of STAT3 signalling. Cardiovasc Res. 2019;115(1):230-42. https://doi.org/10.1093/cvr/cvy206.

29. Gao W, Zhu M, Wang H, Zhao S, Zhao D, Yang Y, et al. Association of polymorphisms in long non-coding RNA H19 with coronary artery disease risk in a Chinese population. Mutat Res Mol Mech Mutagen. 2015;772:15-22.

30. Pan J-X. LncRNA H19 promotes atherosclerosis by regulating MAPK and NF-kB signaling pathway. Eur Rev Med Pharmacol Sci. 2017;21:322-8.

31. Zhang Z, Gao W, Long Q-Q, Zhang J, Li Y-F, Liu D-C, et al. Increased plasma levels of IncRNA H19 and LIPCAR are associated with increased risk of coronary artery disease in a Chinese population. Sci Rep. 2017;7:7491.

32. Zhang L, Cheng H, Yue Y, Li S, Zhang D, He R. H19 knockdown suppresses proliferation and induces apoptosis by regulating $\mathrm{miR}-148 \mathrm{~b} / \mathrm{WNT} / \beta$-catenin in ox-LDL -stimulated vascular smooth muscle cells. J Biomed Sci. 2018;25:11. https:// doi.org/10.1186/s12929-018-0418-4.

33. Bitarafan S, Yari M, Broumand MA, Ghaderian SMH, Rahimi M, Mirfakhraie R, et al. Association of increased levels of lncRNA H19 in PBMCs with risk of coronary artery disease. Cell J. 2019;20:564-8.

34. Choy PC, Mymin D, Zhu Q, Dakshinamurti KOK. Atherosclerosis risk factors: the possible role of homocysteine. Mol Cell Biochem. 2000;207:143-8.

35. Kartal Ozer N, Taha S, Azzi A. Homocysteine induces DNA synthesis and proliferation of vascular smooth muscle cells by interfering with MAPK kinase pathway. Biofactors. 2005;24:193-9.

36. Zou T, Yang W, Hou Z, Yang J. Homocysteine enhances cell proliferation in vascular smooth muscle cells: role of p38 MAPK and p47phox. Acta Biochim Biophys Sin. 2010;42:908-15.

37. Li L, Xie J, Zhang M, Wang S. Homocysteine harasses the imprinting expression of IGF2 and H19 by demethylation of differentially methylated region between IGF2/H19 genes. Acta Biochim Biophys Sin. 2009;41:464-71.

38. Sun W, Lv J, Duan L, Lin R, Li Y, Li S, et al. Long noncoding RNA H19 promotes vascular remodeling by sponging let-7a to upregulate the expression of cyclin D1. Biochem Biophys Res Commun. 2019;508:1038-42.

39. Huang Y, Wang L, Mao Y, Nan G. Long noncoding RNA-H19 contributes to atherosclerosis and induces ischemic stroke via the upregulation of acid phosphatase 5. Front Neurol. 2019;10:32. https://doi.org/10.1186/s12929-018-0418-4.

40. Song Z, Wei D, Chen Y, Chen L, Bian Y, Shen Y, et al. Association of astragaloside IV-inhibited autophagy and mineralization in vascular smooth muscle cells with lncRNA H19 and DUSP5-mediated ERK signaling. Toxicol Appl Pharmacol. 2018;364:45-54.

41. Pasmant E, Laurendeau I, Héron D, Vidaud M, Vidaud D, Bièche I. Characterization of a germ-line deletion, including the entire INK4/ARF locus, in a melanoma-neural system tumor family: 
identification of ANRIL, an antisense noncoding RNA whose expression coclusters with ARF. Cancer Res. 2007;67:3963-9.

42. Holdt LM, Teupser D. Recent studies of the human chromosome 9p21 locus, which is associated with atherosclerosis in human populations. Arterioscler Thromb Vasc Biol. 2012;32:196-206.

43. Hu L, Su G, Wang X. The roles of ANRIL polymorphisms in coronary artery disease: a meta-analysis. Biosci Rep. 2019;2019:1559.

44. Xie Y, Zhao D, Dong P, Wang H, Li D, Lai L. Effects of ANRIL polymorphisms on the likelihood of coronary artery disease: a meta-analysis. J Cell Biochem. 2019;120:6113-9.

45. Holdt LM, Teupser D. Long noncoding RNA ANRIL: Lnc-ing genetic variation at the chromosome 9p21 locus to molecular mechanisms of atherosclerosis. Front Cardiovasc Med. 2018;5:145.

46. Broadbent HM, Peden JF, Lorkowski S, Goel A, Ongen H, Green $\mathrm{F}$, et al. Susceptibility to coronary artery disease and diabetes is encoded by distinct, tightly linked SNPs in the ANRIL locus on chromosome 9p. Hum Mol Genet. 2008;17:806-14.

47. Burd CE, Jeck WR, Liu Y, Sanoff HK, Wang Z, Sharpless NE. Expression of linear and novel circular forms of an INK4/ARFassociated non-coding RNA correlates with atherosclerosis risk. PLoS Gene. 2010;6(12):e1001233. https://doi.org/10.1371/journ al.pgen.1001233.

48. Congrains A, Kamide K, Katsuya T, Yasuda O, Oguro R, Yamamoto K, et al. CVD-associated non-coding RNA, ANRIL, modulates expression of atherogenic pathways in VSMC. Biochem Biophys Res Commun. 2012;419:612-6.

49. Chi J-S, Li J-Z, Jia J-J, Zhang T, Liu X-M, Yi L. Long noncoding RNA ANRIL in gene regulation and its duality in atherosclerosis. J Huazhong Univ Sci Technol Med Sci. 2017;37:816-22.

50. Aarabi G, Zeller T, Heydecke G, Munz M, Schäfer A, Seedorf U. Roles of the Chr.9p21.3 ANRIL locus in regulating inflammation and implications for anti-inflammatory drug target identification. Front Cardiovasc Med. 2018;5:47.

51. Cho H, Shen G-Q, Wang X, Wang F, Archacki S, Li Y, et al. Long noncoding RNA ANRIL regulates endothelial cell activities associated with coronary artery disease by up-regulating CLIP1, EZR, and LYVE1 genes. J Biol Chem. 2019;294:388198. https://doi.org/10.1074/jbc.RA118.005050.

52. Guo F, Tang C, Li Y, Liu Y, Lv P, Wang W, et al. The interplay of LncRNA ANRIL and miR-181b on the inflammation-relevant coronary artery disease through mediating NF- $\mathrm{\kappa B}$ signalling pathway. J Cell Mol Med. 2018;22:5062-75.

53. Zhou X, Han X, Wittfeldt A, Sun J, Liu C, Wang X, et al. Long non-coding RNA ANRIL regulates inflammatory responses as a novel component of NF- $\mathrm{BB}$ pathway. RNA Biol. 2015;13:98-108.

54. Congrains A, Kamide K, Oguro R, Yasuda O, Miyata K, Yamamoto E, et al. Genetic variants at the $9 \mathrm{p} 21$ locus contribute to atherosclerosis through modulation of ANRIL and CDKN2A/B. Atherosclerosis. 2012;220:449-55.

55. Motterle A, Pu X, Wood H, Xiao Q, Gor S, Liang Ng F, et al. Functional analyses of coronary artery disease associated variation on chromosome 9p21 in vascular smooth muscle cells. Hum Mol Genet. 2012;21:4021-9.

56. Holdt LM, Stahringer A, Sass K, Pichler G, Kulak NA, Wilfert $\mathrm{W}$, et al. Circular non-coding RNA ANRIL modulates ribosomal RNA maturation and atherosclerosis in humans. Nat Commun. 2016;7:12429.

57. Holdt LM, Beutner F, Scholz M, Gielen S, Gäbel G, Bergert $\mathrm{H}$, et al. ANRIL expression is associated with atherosclerosis risk at chromosome 9p21. Arterioscler Thromb Vasc Biol. 2010;30:620-7.
58. Yari M, Bitarafan S, Broumand MA, Fazeli Z, Rahimi M, Ghaderian $\mathrm{SMH}$, et al. Association between long noncoding RNA ANRIL expression variants and susceptibility to coronary artery disease. Int J Mol Cell Med. 2018;7:1-7.

59. Feng L, Guo J, Ai F. Circulating long noncoding RNA ANRIL downregulation correlates with increased risk, higher disease severity and elevated pro-inflammatory cytokines in patients with acute ischemic stroke. J Clin Lab Anal. 2019;33:e22629.

60. Shen Z, She Q. Association between the deletion allele of Ins/ Del polymorphism (Rs145204276) in the promoter region of GAS5 with the risk of atherosclerosis. Cell Physiol Biochem. 2018;49:1431-43.

61. Chen L, Yao H, Hui J, Ding S, Fan Y, Pan Y, et al. Global transcriptomic study of atherosclerosis development in rats. Gene. 2016;592:43-8.

62. Ye J, Wang C, Wang D, Yuan H. LncRBA GSA5, up-regulated by ox-LDL, aggravates inflammatory response and MMP expression in THP-1 macrophages by acting like a sponge for miR-221. Exp Cell Res. 2018;369:348-55.

63. Liang W, Fan T, Liu L, Zhang L. Knockdown of growth-arrest specific transcript 5 restores oxidized low-density lipoproteininduced impaired autophagy flux via upregulating miR-26a in human endothelial cells. Eur J Pharmacol. 2019;843:154-61.

64. Yin Q, Wu A, Liu M. Plasma long non-coding RNA (lncRNA) GAS5 is a new biomarker for coronary artery disease. Med Sci Monit Int Med J Exp Clin Res. 2017;23:6042-8.

65. Li X, Hou L, Cheng Z, Zhou S, Qi J, Cheng J. Overexpression of GAS5 inhibits abnormal activation of Wnt $/ \beta$-catenin signaling pathway in myocardial tissues of rats with coronary artery disease. J Cell Physiol. 2018;234:11348-59. https://doi. org/10.1002/jcp.27792.

66. Wang Y-N-Z, Shan K, Yao M-D, Yao J, Wang J-J, Li X, et al. Long noncoding RNA-GAS5: a novel regulator of hypertensioninduced vascular remodeling. Hypertension. 2016;68:736-48. https://doi.org/10.1161/HYPERTENSIONAHA.116.07259

67. Chen L, Yang W, Guo Y, Chen W, Zheng P, Zeng J, et al. Exosomal lncRNA GAS5 regulates the apoptosis of macrophages and vascular endothelial cells in atherosclerosis. PloS One. 2017;12:e0185406.

68. Yang X, Pan Y, Xu X, Tong T, Yu S, Zhao Y, et al. Sialidase deficiency in Porphyromonas gingivalis increases IL-12 secretion in stimulated macrophages through regulation of CR68, IncRNA GAS5 and miR-21. Front Cell Infect Microbiol. 2018;8:100.

69. Yan Y-Y, Wang Z-H, Zhao L, Song D-D, Qi C, Liu L-L, et al. MicroRNA-210 plays a critical role in the angiogenic effect of isoprenaline on human umbilical vein endothelial cells via regulation of noncoding RNAs. Chin Med J (Engl). 2016;129:2676-82.

70. Ishii N, Ozaki K, Sato H, Mizuno H, Saito S, Takahashi A, et al. Identification of a novel non-coding RNA, MIAT, that confers risk of myocardial infarction. J Hum Genet. 2006;51:1087-99.

71. Ohnishi Y, Tanaka T, Yamada R, Suematsu K, Minami M, Fujii $\mathrm{K}$, et al. Identification of 187 single nucleotide polymorphisms (SNPs) among 41 candidate genes for ischemic heart disease in the Japanese population. Hum Genet. 2000;106:288-92.

72. Ye Z, Yang S, Xia Y, Hu R, Chen S, Li B, et al. LncRNA MIAT sponges miR-149-5p to inhibit efferocytosis in advanced atherosclerosis through CD47 upregulation. Cell Death Dis. 2019;10:138

73. Zhong X, Ma X, Zhang L, Li Y, Li Y, He R. MIAT promotes proliferation and hinders apoptosis by modulating miR-181b/ STAT3 axis in ox-LDL-induced atherosclerosis cell models. Biomed Pharmacother. 2018;97:1078-85.

74. Hennessy EJ, van Solingen C, Scacalossi KR, Ouimet M, Afonso MS, Prins J, et al. The long noncoding RNA CHROME regulates cholesterol homeostasis in primates. Nat Metab. 2019;1:98-110. 
75. Ballantyne MD, Pinel K, Dakin R, Vesey AT, Diver L, Mackenzie $\mathrm{R}$, et al. Smooth muscle enriched long noncoding RNA (SMILR) regulates cell proliferation. Circulation. 2016;133:2050-65.

76. Lim Y-H, Kwon D-H, Kim J, Park WJ, Kook H, Kim Y-K. Identification of long noncoding RNAs involved in muscle differentiation. PLoS One. 2018;13:e0193898.

77. Zhang D-D, Wang W-T, Xiong J, Xie X-M, Cui S-S, Zhao Z-G, et al. Long noncoding RNA LINC00305 promotes inflammation by activating the AHRR-NF- $\kappa \mathrm{B}$ pathway in human monocytes. Sci Rep. 2017;7:46204.

78. Zhang B-Y, Jin Z, Zhao Z. Long intergenic noncoding RNA 00305 sponges miR-136 to regulate the hypoxia induced apoptosis of vascular endothelial cells. Biomed Pharmacother. 2017;94:238-43.

79. Shan K, Jiang Q, Wang X-Q, Wang Y-N-Z, Yang H, Yao M-D, et al. Role of long non-coding RNA-RNCR3 in atherosclerosisrelated vascular dysfunction. Cell Death Dis. 2016;7:e2248.

80. Flockhart RJ, Webster DE, Qu K, Mascarenhas N, Kovalski J, Kretz M, et al. BRAFV600E remodels the melanocyte transcriptome and induces BANCR to regulate melanoma cell migration. Genome Res. 2012;22:1006-14.

81. Li H, Liu X, Zhang L, Li X. LncRNA BANCR facilitates vascular smooth muscle cell proliferation and migration through JNK pathway. Oncotarget. 2017;8:114568-75.

82. Wang KC, Yang YW, Liu B, Sanyal A, Corces-Zimmerman $\mathrm{R}$, Chen $\mathrm{Y}$, et al. A long noncoding RNA maintains active chromatin to coordinate homeotic gene expression. Nature. 2011;472:120-4.

83. Liao B, Chen R, Lin F, Mai A, Chen J, Li H, et al. Long noncoding RNA HOTTIP promotes endothelial cell proliferation and migration via activation of the $\mathrm{Wnt} / \beta$-catenin pathway. J Cell Biochem. 2018;119:2797-805.

84. Wang X, Zhao Z, Zhang W, Wang Y. Long noncoding RNA LINC00968 promotes endothelial cell proliferation and migration via regulating miR-9-3p expression. J Cell Biochem. 2018;120:8214-8221.

85. Moreau PR, Örd T, Downes NL, Niskanen H, Bouvy-Liivrand M, Aavik E, et al. Transcriptional profiling of hypoxia-regulated non-coding RNAs in human primary endothelial cells. Front Cardiovasc Med. 2018;5:159.

86. Ji P, Diederichs S, Wang W, Böing S, Metzger R, Schneider PM, et al. MALAT- 1 , a novel noncoding RNA and thymosin $\beta 4$ predict metastasis and survival in early-stage non-small cell lung cancer. Oncogene. 2003;22:8031-41.

87. Cremer S, Michalik KM, Fischer A, Pfisterer L, Jaé N, Winter $\mathrm{C}$, et al. Hematopoietic deficiency of the long noncoding RNA MALAT1 promotes atherosclerosis and plaque inflammation. Circulation. 2019;139:1320-34

88. Zhu Y, Yang T, Duan J, Mu N, Zhang T. MALAT1/miR-15b-5p/ MAPK1 mediates endothelial progenitor cells autophagy and affects coronary atherosclerotic heart disease via mTOR signaling pathway. Aging. 2019;11:1089-109.

89. Michalik KM, You X, Manavski Y, Doddaballapur A, Zörnig $\mathrm{M}$, Braun $\mathrm{T}$, et al. Long noncoding RNA MALAT1 regulates endothelial cell function and vessel growth. Circ Res. 2014;114:1389-97.

90. Kölling M, Genschel C, Kaucsar T, Hübner A, Rong S, Schmitt $\mathrm{R}$, et al. Hypoxia-induced long non-coding RNA Malat1 is dispensable for renal ischemia/reperfusion-injury. Sci Rep. 2018;8:3438.

91. Zeng R, Zhang R, Song X, Ni L, Lai Z, Liu C, et al. The long non-coding RNA MALAT1 activates Nrf2 signaling to protect human umbilical vein endothelial cells from hydrogen peroxide. Biochem Biophys Res Commun. 2018;495:2532-8.

92. Tang Y, Jin X, Xiang Y, Chen Y, Shen C, Zhang Y, et al. The IncRNA MALAT1 protects the endothelium against
ox-LDL-induced dysfunction via upregulating the expression of the miR-22-3p target genes CXCR92 and AKT. FEBS Lett. 2015;589:3189-96.

93. Li S, Sun Y, Zhong L, Xiao Z, Yang M, Chen M, et al. The suppression of ox-LDL-induced inflammatory cytokine release and apoptosis of HCAECs by long non-coding RNA-MALAT1 via regulating microRNA-155/SOCS1 pathway. Nutr Metab Cardiovasc Dis NMCD. 2018;28:1175-87.

94. Puthanveetil P, Chen S, Feng B, Gautam A, Chakrabarti S. Long non-coding RNA MALAT1 regulates hyperglycaemia induced inflammatory process in the endothelial cells. J Cell Mol Med. 2015;19:1418-25.

95. Song Y, Yang L, Guo R, Lu N, Shi Y, Wang X. Long noncoding RNA MALAT1 promotes high glucose-induced human endothelial cells pyroptosis by affecting NLRP3 expression through competitively binding miR-22. Biochem Biophys Res Commun. 2019;509:359-66.

96. Evrard SM, Lecce L, Michelis KC, Nomura-Kitabayashi A, Pandey G, Purushothaman K-R, et al. Endothelial to mesenchymal transition is common in atherosclerotic lesions and is associated with plaque instability. Nat Commun. 2016;7:11853.

97. Li H, Zhao Q, Chang L, Wei C, Bei H, Yin Y, et al. LncRNA MALAT1 modulates ox-LDL induced EndMT through the Wnt/ $\beta$-catenin signaling pathway. Lipids Health Dis. 2019;18:62.

98. Xiang Y, Zhang Y, Tang Y, Li Q. MALAT1 modulates TGF- $\beta 1$ induced endothelial-to-mesenchymal transition through downregulation of miR-145. Cell Physiol Biochem. 2017;42:357-72.

99. Zhao G, Su Z, Song D, Mao Y, Mao X. The long noncoding RNA MALAT1 regulates the lipopolysaccharide-induced inflammatory response through its interaction with NF- $\mathrm{BB}$. FEBS Lett. 2016;590:2884-95.

100. Huangfu N, Xu Z, Zheng W, Wang Y, Cheng J, Chen X. LncRNA MALAT1 regulates oxLDL-induced CD36 expression via activating $\beta$-catenin. Biochem Biophys Res Commun. 2018;495:2111-7.

101. Brock M, Schuoler C, Leuenberger C, Bühlmann C, Haider TJ, Vogel J, et al. Analysis of hypoxia-induced noncoding RNAs reveals metastasis-associated lung adenocarcinoma transcript 1 as an important regulator of vascular smooth muscle cell proliferation. Exp Biol Med. 2017;242:487-96.

102. Yu C, Xu T, Assoian R, Rader DJ. Mining the stiffness-sensitive transcriptome in human vascular smooth muscle cells identifies long non-coding RNA stiffness regulators. Arterioscler Thromb Vasc Biol. 2018;38:164-73.

103. Bell RD, Long X, Lin M, Bergmann JH, Nanda V, Cowan SL, et al. Identification and initial functional characterization of a human vascular cell enriched long non-coding RNA. Arterioscler Thromb Vasc Biol. 2014;34:1249-59.

104. Boulberdaa M, Scott E, Ballantyne M, Garcia R, Descamps B, Angelini GD, et al. A role for the long noncoding RNA SENCR in commitment and function of endothelial cells. Mol Ther. 2016;24:978-90.

105. Lyu Q, Xu S, Lyu Y, Choi M, Christie CK, Slivano OJ, et al. SENCR stabilizes vascular endothelial cell adherens junctions through interaction with CKAP4. Proc Natl Acad Sci USA. 2019;116:546-55.

106. Shahmoradi N, Nasiri M, Kamfiroozi H, Kheiry MA. Association of the rs555172 polymorphism in SENCR long non-coding RNA and atherosclerotic coronary artery disease. J Cardiovasc Thorac Res. 2017;9:170-4.

107. Ziaee S, Boroumand MA, Salehi R, Sadeghian S, Hosseindokht M, Sharifi M. Non-invasive diagnosis of early-onset coronary artery disease based on cell type-specific gene expression analyses. Biomed Pharmacother Biomedecine Pharmacother. 2018;108:1115-22. 
108. Huarte M, Guttman M, Feldser D, Garber M, Koziol MJ, Kenzelmann-Broz D, et al. A large intergenic non-coding RNA induced by 553 mediates global gene repression in the 553 response. Cell. 2010;142:409-19.

109. Chillón I, Pyle AM. Inverted repeat Alu elements in the human lincRNA-p21 adopt a conserved secondary structure that regulates RNA function. Nucleic Acids Res. 2016;44:9462-71.

110. Tang S, Cheng J, Cai M, Yang X, Liu X, Zheng B, et al. Association of lincRNA-p21 haplotype with coronary artery disease in a Chinese han population. Dis Markers. 2016;2016:9109743. https ://doi.org/10.1155/2016/9109743.

111. Wu G, Cai J, Han Y, Chen J, Huang Z-P, Chen C, et al. LincRNAp21 regulates neointima formation, vascular smooth muscle cell proliferation, apoptosis, and atherosclerosis by enhancing p53 activity. Circulation. 2014;130:1452-65.

112. Çekin N, Özcan A, Göksel S, Arslan S, Pınarbaşı E, Berkan Ö. Decreased FENDRR and LincRNA-p21 expression in atherosclerotic plaque. Anatol J Cardiol. 2018;19:131-6.

113. Hu W, Wang Z, Li Q, Wang J, Li L, Jiang G. Upregulation of lincRNA-p21 in thoracic aortic aneurysms is involved in the regulation of proliferation and apoptosis of vascular smooth muscle cells by activating TGF- $\beta 1$ signaling pathway. J Cell Biochem. 2019;120:4113-20.

114. Hajjari M, Salavaty A. HOTAIR: an oncogenic long non-coding RNA in different cancers. Cancer Biol Med. 2015;12:1-9.

115. Peng Y, Meng K, Jiang L, Zhong Y, Yang Y, Lan Y, et al. Thymic stromal lymphopoietin-induced HOTAIR activation promotes endothelial cell proliferation and migration in atherosclerosis. Biosci Rep. 2017;37:BSR20170351.

116. Lin J, Chang W, Dong J, Zhang F, Mohabeer N, Kushwaha KK, et al. Thymic stromal lymphopoietin over-expressed in human atherosclerosis: potential role in Th17 differentiation. Cell Physiol Biochem. 2013;31:305-18.

117. Liu J, Huang G-Q, Ke Z-P. Silence of long intergenic noncoding RNA HOTAIR ameliorates oxidative stress and inflammation response in ox-LDL-treated human macrophages by upregulating miR-330-5p. J Cell Physiol. 2019;234:5134-42.
118. Pang J-L, Wang J-W, Hu P-Y, Jiang J-S, Yu C. HOTAIR alleviates ox-LDL-induced inflammatory response in Raw264.7 cells via inhibiting NF-кB pathway. Eur Rev Med Pharmacol Sci. 2018;22:6991-8.

119. Avazpour N, Hajjari M, Yazdankhah S, Sahni A, Foroughmand AM. Circulating HOTAIR RNA is potentially up-regulated in coronary artery disease. Genomics Inform. 2018;16:e25.

120. Hu Y-W, Guo F-X, Xu Y-J, Li P, Lu Z-F, McVey DG, et al. Long noncoding RNA NEXN-AS1 mitigates atherosclerosis by regulating the actin-binding protein NEXN. J Clin Invest. 2019;129:1115-28.

121. Wu C, Yan H, Sun J, Yang F, Song C, Jiang F, et al. NEXN Is a novel susceptibility gene for coronary artery disease in Han Chinese. PLoS One. 2013;8:e82135.

122. Zhang Y, Zheng L, Xu B-M, Tang W-H, Ye Z-D, Huang C, et al. LncRNA-RP11-714G18.1 suppresses vascular cell migration via directly targeting LRP2BP. Immunol Cell Biol. 2018;96:175-89.

123. Meng F, Yan J, Ma Q, Jiao Y, Han L, Xu J, et al. Expression status and clinical significance of lncRNA APPAT in the progression of atherosclerosis. Peer J. 2018;6:e4246. https://doi. org/10.7717/peerj.4246.

124. Grote P, Wittler L, Währisch S, Hendrix D, Beisaw A, Macura K, et al. The tissue-specific lncRNA Fendrr is an essential regulator of heart and body wall development in the mouse. Dev Cell. 2013;24:206-14.

125. Lv J, Wang L, Zhang J, Lin R, Wang L, Sun W, et al. Long noncoding RNA H19-derived miR-675 aggravates restenosis by targeting PTEN. Biochem Biophys Res Commun. 2018;497:1154-61.

126. Holdt LM, Hoffmann S, Sass K, Langenberger D, Scholz M, Krohn K, et al. Alu elements in ANRIL non-coding RNA at chromosome 9p21 modulate atherogenic cell functions through transregulation of gene networks. PLoS Genet. 2013;9:e1003588.

127. Yan B, Yao J, Liu J-Y, Li X-M, Wang X-Q, Li Y-J, et al. lncRNAMIAT regulates microvascular dysfunction by functioning as a competing endogenous RNA. Circ Res. 2015;116:1143-56. 